\title{
Eräiden rikkakasvihävitteiden teho perunalla
}

\author{
Syvälahti, J., Ylänen, M. ja Leskelä, A. \\ Kemira Oy, Helsinki
}

\section{Effect of some herbicides in potato}

SyväLahti, J., Ylänen, M. and Leskelä, A.

Kemira Oy, Helsinki, Finland

\begin{abstract}
Compared to the untreated control the use fo various herbicides has given yield increases of 6-11 tons per hectare. Prometryne (Gesagard 50) and terbutryne (Igran 50) gave highly significant differences in results compared to the untreated control. The effects of various chemicals, however, did not differ from each other significantly. On the average, the best weed control and highest yield increases were obtained with linuron, followed by terbutryne and prometryn. Results of MCPA and cyanazine were not as good. Prometryne and cyanazine did not have an equally good effect on weeds, and probably for this reason, they did not give good yield results consistently.
\end{abstract}

Viime vuosina perunan viljelyala on maassamme ollut n. 50000 ha. Rikkakasvien torjunta on hoidettu suurimmaksi osaksi mekaanisesti, harauksin ja multauksin. Erilaiset torjunta-aineet tarjoavat nykyisin rikkakasvien hävitykseen myös kemiallisen mahdollisuuden. Niinpä niiden käyttöä onkin tutkittu jo yli kymmenen vuotta ja verrattu mekaanisia ja kemiallisia menetelmiä toisiinsa (Marttila 1967, Huokuna ja Lindroos 1972, Mäntylahti ym. 1972). Näissä tutkimuksissa on todettu rikkakasvihävitteillä saatavan sadonlisäyksiä, jotka riippuvat suuresti rikkakasvien määrästä. Mitä enemmän rikkakasveja esiintyi, sitä alempi oli satotaso. Rikkakasvien torjunnalla saadut sadonlisäykset taas olivat tällöin suhteellisesti suurempia. Maavaikutteisten herbisidien ollessa kyseessä ovat myös ilmasto ja maaperän ominaisuudet tulokseen vaikuttavia tekijöitä (THORUP 1971).

Tässä tutkimuksessa on selvitetty eräiden rikkakasvihävitteiden vaikutusta rikkakasvien määrään ja perunan satoon.

\section{Koeaineisto}

Kokeet suoritettiin Kemira Oy:n koetilalla Kotkaniemessä 1966-1967, 1970-1973. Koealueen maalaji oli pääosin hietaa. Lannoituksena käytettiin kahtena ensimmäisenä vuotena Kloorivapaata Y-lannosta $(5 \% \mathrm{~N}-12 \%$ 
Taulukko 1. Rikkakasvien torjuntakokeet perunalla vv. 1966-1973 Kotkaniemessä. Perunasadot kg/ha. Table 1. Results of control trials on potato at Kotkaniemi experimental farm during 1966-1973. Potato yields, kg/ha.

\begin{tabular}{|c|c|c|c|c|c|c|c|c|c|c|}
\hline $\begin{array}{c}\text { Torjunta-aine } \\
\text { Treatments }\end{array}$ & 1966 & 1967 & 1970 & 1971 & 1972 & $\begin{array}{cc} & 1 \\
\text { koe } & \mathrm{I} \\
\text { trial } & I\end{array}$ & $\begin{array}{l}1973 \\
\text { I koe II } \\
\text { I trial II }\end{array}$ & $\begin{array}{l}\text { Keskim. } \\
\text { Average }\end{array}$ & $\begin{array}{l}\text { Mittari } \\
\text { Control }\end{array}$ & $\begin{array}{c}\text { Sadonlisäys } \\
\text { Yield increase } \\
\text { tn/ha }\end{array}$ \\
\hline $\begin{array}{l}\text { Käsittelemätön ............ } \\
\text { Untreated control }\end{array}$ & 2050 & 8170 & 12140 & 14330 & 14090 & 23420 & 19900 & 13445 & - & - \\
\hline $\begin{array}{l}\text { Linuroni } \ldots \ldots \ldots \ldots \ldots \ldots \\
\text { Linuron }\end{array}$ & 17140 & - & 26720 & 26690 & 16760 & - & - & 21644 & 10653 & 11.0 \\
\hline $\begin{array}{l}\text { Prometryyni .............. } \\
\text { Prometryne }\end{array}$ & 14860 & 13450 & 20250 & 25560 & 17540 & - & - & 19285 & 10156 & 9.1 \\
\hline $\begin{array}{l}\text { MCPA } \\
M C P A\end{array}$ & 14380 & - & 18540 & 21660 & - & - & 21160 & 18935 & 12105 & 6.8 \\
\hline $\begin{array}{l}\text { Terbutryyni } . . . . . . . . . . . \\
\text { Terbutryne }\end{array}$ & - & 15800 & 24820 & 27640 & 18210 & 28790 & 33300 & 24760 & 15342 & 9.4 \\
\hline 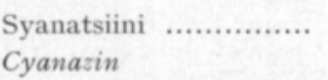 & - & - & - & 27960 & 11830 & - & - & $(19895)$ & $(14210)$ & $(5.7)$ \\
\hline
\end{tabular}

Tilastollisia arvoja: käsittelemätön/linuroni $\mathrm{F}=15.0^{*} \quad \mathrm{~s}_{\mathbf{x}}^{-}=12.6 \%$

Statistical treatment: untreated/linuron

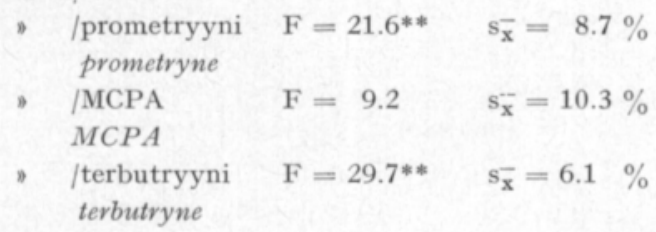

Kemiallisten käsittelyjen välillä ei ole tilastollisesti merkitseviä eroja. No significant differences between the chemical treatments.

$\left.\mathrm{P}_{2} \mathrm{O}_{5}-15 \% \mathrm{~K}_{2} \mathrm{O}\right) 1200$ ja $1500 \mathrm{~kg} / \mathrm{ha}$. Myöhempinä vuosina lannoite oli Kloorivapaa Super Y-lannos $\left(\begin{array}{llllll}7 \% & \mathrm{~N}-24 \% & \mathrm{P}_{2} \mathrm{O}_{5}-14 \% & \left.\mathrm{~K}_{2} \mathrm{O}\right) & 800-\end{array}\right.$ $1000 \mathrm{~kg} / \mathrm{ha}$. Perunalajike oli Bintje muina vuosina paitsi 1966-1967, jolloin se oli Olympia. Kaikissa ruiskutuksissa vesimäärä oli 400 1/ha ja koeruudun koko $2.1 \times 20 \mathrm{~m}$ eli 3 riviä. Kerranteita oli 3-4. Rikkakasvihävitteitä käytettiin seuraavia määriä: prometryyniä (Gesagard 50) $1.50-1.75 \mathrm{~kg} / \mathrm{ha}$, linuronia (Perunan Rikkaruohontuho) $1.5 \mathrm{~kg} / \mathrm{ha}$, MCPA (Hormotuho) $1.0-1.25 \mathrm{~kg} / \mathrm{ha}$, terbutryyniä (Igran 50) $1.5 \mathrm{~kg} / \mathrm{ha}$ ja syanatsiinia (Bladex) $1.5-3.0 \mathrm{~kg} / \mathrm{ha}$. Kaikki aineet ruiskutettiin istutuksen jälkeen juuri ennen perunan taimettumista. Rikkakasvilaskennat suoritettiin syksyllä hyvissä ajoin ennen sadonkorjuuta. Rikkakasvien rehevyysprosentti arvosteltiin silmävaraisesti asteikolla $0-100$ siten, että 100 tarkoittaa tilannetta, jolloin rikkakasvusto peitti maan kauttaaltaan ja 0 tilannetta, jolloin rikkakasveja ei esiintynyt. 


\section{Tulokset}

Eri torjunta-aineilla vuosittain saadut perunasadot esitetään taulukossa 1 samoin kuin eri käsittelyjen keskiarvotulokset ja sadonlisäykset. Käsittelemättömään verrattuna kemiallisten hävitteiden käyttö antoi sadonlisäystä 6-11 tn/ha. Tilastollisesti selvimmät erot käsittelemättömään verrattuna ovat olleet prometryynillä (Gesagard 50) ja terbutryynillä (Igran 50). Eri kemikaalien välillä ei tässä aineistossa sen sijaan ole tilastollisia eroja. Kemikaaleista kuitenkin syanatsiini näyttää olleen heikoin. Piirroksessa 1 esitetään

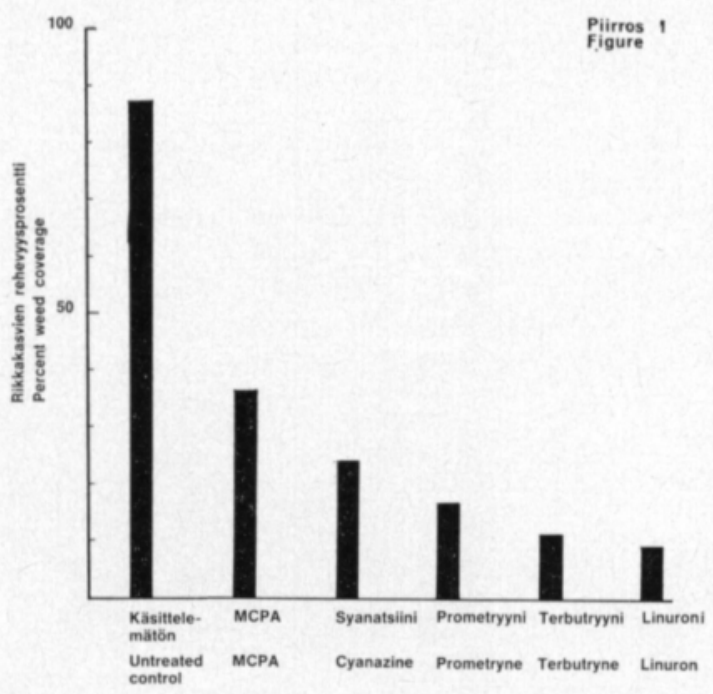

Kuva 1. Rikkakasvien rehevyys torjunta-ainekokeissa perunalla.

Figure 1. Percent weed coverage in herbicide trials for potato.

Rikkakasvien rehevyysprosentti $100 \%$ = rikkakasvusto peittää maan kauttaaltaan Percent weed coverage

$$
=\text { totàl weed coverage }
$$

$0 \%=$ rikkakasveja ei lainkaan

$$
=\text { no weeds }
$$

vastaavasti rikkakasvien rehevyysprosentti. Parhaiten rikkakasveihin tehoavia aineita ovat olleet linuroni ja terbutryyni, sitten prometryyni, syanatsiini ja MCPA. Päärikkakasveina ovat olleet pelto-orvokki, pillikkeet, linnunkaali, tatarlajit, peltokorte ja peltohatikka.

Mitä enemmän rikkakasveja esiintyi, sitä alempi oli käsittelemättömien

\begin{tabular}{|c|c|c|c|c|c|}
\hline 1966 & 사. & 2.050 & $\mathrm{~kg} / \mathrm{ha}$ & 90 & rehevyys-\% \\
\hline 1967 & …................. & 8.170 & , & 100 & , \\
\hline 1970 & & 12.140 & , & 97 & • \\
\hline 1971 & .... & 14.330 & , & 86 & , \\
\hline 1972 & …………..... & 14.090 & , & 80 & , \\
\hline 1973 & n.................. & 23.420 & , & 58 & , \\
\hline 1973 & ..... & 19.900 & , & 78 & - \\
\hline
\end{tabular}
ruutujen sato: 
Tulokset ovat MCPA:n ja linuronin suhteen samansuuntaisia kuin muissakin (Huokuna ja Lindroos 1972, Mäntylahti ym. 1972) tutkimuksissa on saatu. Sen sijaan prometryyni, syanatsiini ja terbutryyni ovat uusia aineita, joita ei ole em. kokeissa ollut mukana. Terbutryyni on tässä koersarjassa (6 v.) antanut tasaisesti hyviä tuloksia kuten linuronikin. Prometryyni ja syanatsiini eivät ole tehonneet yhtä hyvin rikkakasveihin ja satotulos on ilmeisesti tämän takia ollut epätasaisempi.

\section{KIRJALLISUUSLUETTELO}

HUokUnA, E. \& Lindroos, N. 1972. Perunan rikkakasvien kemiallinen torjunta. Koetoim. ja Käyt. 29, 3:9, 11.

MARTTILA, M. 1967. Rikkakasvihävitteiden käyttömahdollisuudet perunan viljelyssä. Maatal. ja Koetoim. 21: 177-182.

Mäntylahtı, V., Lindroos, N. \& HuokUna, E. 1972. Perunanviljelysten kemiallinen rikkakasvintorjunta. Kehittyvä Maatalous 10:3-25.

ThоRUP, S. 1971. Ukrudtsbekaempelse i kartofler. NJF-kongr. Seksjon II: 24-28. 